\begin{tabular}{|c|c|c|}
\hline $\begin{array}{c}\text { Editorial \& Publishing Offices : } \\
\text { MACMILLAN \& Co., LTD. } \\
\text { ST. MARTIN's STREET } \\
\text { LONDON, W.C.2 }\end{array}$ & & $\begin{array}{l}\text { Telegraphic Address : } \\
\text { Phusis, LesQuare, London } \\
\text { Telephone Number: } \\
\text { WhITEHALI } 88_{3} \mathrm{I}\end{array}$ \\
\hline Vol. 146 & SATURDAY, NOVEMBER 2, I940 & No. 3705 \\
\hline
\end{tabular}

\title{
COLONIAL FORESTRY AND COUNTRYSIDE PROBLEMS
}

$\mathrm{B}^{\mathrm{U}}$ T a short while ago this heading would have been written in an inverse order, that is, countryside problems and forestry, the greater stress being laid on the former. In some matters, the British are ultra-conservative; the more so perhaps where ignorance of a subject leads them to an instinctive opposition and disinclination to move in a, to them, unknown direction. In no department of administration has this national trait become more evident than the forestry departments throughout the Empire. India early broke loose from this official inertia, owing to a fortunate combination of clear-headed, widevisioned Secretaries of State and competent Governors-General. The extensive, valuable and well-administered Indian forests are witness to this fact.

In the Colonial Forest Services, on the other hand, a very different position had gradually arisen. Forestry was completely misunderstood. It was thought that totally undeveloped areas of existing forests, supervised by small inadequate staffs, should pay their way almost from the start or they were not worth the trouble and expense of administration. The Secretary of State left matters to the individual and constantly changing Governors, who, with no knowledge of forestry principles, were for the most part guided by their financial advisers ; these latter regarded a forestry department merely as a potential source of revenue, the expenditure of which was ruthlessly cut when for various perfectly justifiable, in fact often obvious, reasons, the anticipated revenue was not forthcoming.
Although lip service had been given in expressions of opinion on the value of forests and their protection, etc., until well within the last decade there had been no real attempt at a continuity of management, with one or two notable exceptions, in the forestry services under the Colonial Office. An awakening had commenced and the present War appears to have hastened it.

The annual report of the Uganda Forest Department for the year ending December 31, 1939 (Entebbe, Govt. Printer, 1940) opens with a quotation from the Secretary of State for the Colonies (taken from "The Colonial Empire," Cmd. 6023, 1939) as follows: "Forestry Departments are becoming more and more involved in the study of general rural development and land use and contacts between them and other departments engaged on similar work have been strengthened.'

In his introduction, the conservator of forests, Mr. N. V. Brasnett, who had been working closely with the director of the Geological Survey of the Protectorate, enunciates once again the timehonoured principles of a forest policy dealing with forest reservation; obtaining the best financial return for the forest estate; encouragement to private forestry, whether by native enterprise or private individuals; and propaganda towards giving the people a knowledge of the value of forests both to themselves and to their posterity. There appears to be hope that Uganda, in spite of the War, will now be granted the facilities to put in force, practically, these articles of the forestry creed. 
In the annual report of the Forestry Department for Nyasaland for the year ending December 31, 1939 (Zomba, Nyasaland, Govt. Printer, 1940) the Conservator, Mr. J. B. Clements, develops the same theme.

It is pointed out that the outbreak of War has enbanced the need for making the Protectorate independent of imported soft woods, and particular attention has been given to means of increasing the outturn of local timbers for building purposes, both hard wood and planted soft wood, in anticipation of increased demands. The village forest area scheme is providing a valuable reserve of poles and firewood near the villages themselves which did not exist a few years ago. This enables the urban natives to obtain these materials at low rates from forest reserves near the townships-a benefit now becoming appreciated by those responsible for the administration of improvident populations in tropical countries.

In the connexion here dealt with, the following depicts the new position as regards the forests, which is acquiring definite recognition. Alluding to a draft revision of forest legislation during the year, the Conservator says that the revision had become necessary for two reasons : (a) the change in status of various classes of land (native forest land) brought about by the Order in Council, 1936; and $(b)$ the need for the gradual devolution of responsibility for forest protection and manage- ment to native authorities, and for their participation in a share of forest revenue. The Agronomic Sub-Committee of the Native Welfare Committee simultaneously put forward suggestions to Government for the enaction of legislation to implement soil conservation policy relating to all classes of land.

These proposals, together with those for the revised forest legislation, mark an important stage in efforts towards reform, and bring new emphasis on land conservation both as regards the selection of land for various purposes, and the conservative treatment of lands selected for agriculture and grazing. The land protection involved in forest policy, namely, the constitution of forest reserves in important catchment areas and watersheds, the closure to cultivation of steep hill slopes which in many cases become village forest areas, the enforcement of stream bank regulations, forms a really satisfactory nucleus for complete land planning in very many regions.

This encouraging departure, which in one form or another is making its appearance in other parts of Africa, will need the most careful supervision on the part of Governors, the civil administration and the Conservators, if it is to justify the high hopes which its introduction gives rise to. The education of populations accustomed from time immemorial to treat the forests as a property of no value will not be completed in a day.

\section{CULTURE OF THE NUER}

The Nuer

A Description of the Modes of Livelihood and Political Institutions of a Nilotic People. By Dr. E. E. Evans-Pritchard. Pp. xii $+271+30$ plates. (Oxford : Clarendon Press ; London : Oxford University Press, 1940.) 17s. 6d. net.

TO understand Dr. Evans-Pritchard's admirable account of the Nuer, a pastoral group inhabiting the swampy lowlands south of the junction of the Nile with the Sobat and Bahr el Ghazal, one must learn to think in terms of ox or cow (the ambiguity of these words in the English language showing how far we have degenerated in this respect). For it is explained that "their social idiom is a bovine idiom". Thus their difficult cattle terminology of colour, age and sex-the colour scheme is given us in a dozen striking diagrams - affords the chief clue to their marriage arrangements, ritual and law. Even kinship, that basic fact in the sociology of any primitive community, is customarily defined by reference to payments of cows in the form of dowries and other wedding-presents; so that "movements of cattle from kraal to kraal are equivalent to lines on a genealogical chart".

Thus this study by Dr. Evans-Pritchard, which is singularly successful in harmonizing a descriptive with an analytic interest, moves naturally forward from an examination of the ecology - - that is, the economic life as determined by the physical conditions and state of the arts-to a review of the social organization as consisting in three complementary elements, the political system, the lineage system, and a peculiar system of 'age-sets', the sentimental bond uniting fellow initiates. The book, then, is remarkably compact, and the author is much to be commended for achieving so neat a 